\title{
Dizziness Control in Virtual Reality by Vibration Stimulation in Mastoid
}

\author{
Minsuk Chae ${ }^{1}$, Juyong Kang ${ }^{2}$, and Eunsub Lee ${ }^{1}$ D \\ ${ }^{I}$ Department of Otorhinolaryngology, Nowon Eulji Medical Center, Eulji University School of Medicine, Seoul; and \\ ${ }^{2}$ Myungdong Yonsei Clinic, Seoul, Korea
}

\section{가상현실 환경에서 유양돌기에 대한 진동자극이 어지러움 조절에 미치는 영향}

\author{
채민석 ${ }^{1} \cdot$ 강주용 $^{2} \cdot$ 이은섭 ${ }^{1}$ \\ ${ }^{1}$ 을지대학교 의과대학 노원을지대학교병원 이비인후과학교실, ${ }^{2}$ 명동연세이비인후과
}

\author{
Received August 1, 2021 \\ Revised October 20,2021 \\ Accepted November 4, 2021 \\ Address for correspondence \\ Eunsub Lee, MD \\ Department of Otorhinolaryngology, \\ Eulji Medical Center, \\ Eulji University School of Medicine \\ 68 Hangeulbiseok-ro, Nowon-gu, \\ Seoul 01830, Korea \\ Tel $+82-2-970-8276$ \\ Fax $+82-2-970-8275$ \\ E-mail mobfminor@hanmail.net
}

Background and Objectives Virtual reality (VR) users have prevalently experienced motion sickness called cybersickness. Recently, it has been suggested that stimulating the mastoid by vibration relieves cybersickness. This study aimed to verify this proposition.

Subjects and Method Fifty-four young male adults (aged 18 to 27 years) without any experience of severe motion sickness or cybersickness participated in this study. Participants were divided in half into two groups, the experimental group and control group. The experimental group used VR with mastoid vibration, and the control group experienced VR without mastoid vibration. Participants responded to the simulator sickness questionnaire (SSQ) to quantify cybersickness.

Results The total severity scores of cybersickness in the experimental group ranged from 0 to 183.3 with the mean value of $46.7 \pm 49.0$. The total severity scores of cybersickness in the control group ranged from 0 to 194.9 with the mean value of $44.9 \pm 45.1$. There were no significant differences between the two groups.

Conclusion There was no improvement of cybersickness in the VR participants when the mastoid was stimulated by vibration. However, cybersickness might be relieved with changes in the VR condition or vibration settings.

Korean J Otorhinolaryngol-Head Neck Surg 2021;64(12):874-9

Keywords Cybersickness; Dizziness; Vibration stimulation; Virtual reality.
서 론

가상현실(virtual reality, VR)이란, '컴퓨터에서 제공하는 시각과 음향 등의 감각자극을 통해 경험하는 인위적인 환경' 으로 정의할 수 있다. ${ }^{1)}$ 양안시를 이용해 입체영상을 구현하는 VR의 개념은 1832 년 Wheatstone이 거울을 이용해 발명한 스테레오스코프가 최초이며, 1950년대에 현재 쓰이는 것과

This is an Open Access article distributed under the terms of the Creative Commons Attribution Non-Commercial License (https://creativecommons.org/licenses/by-nc/4.0) which permits unrestricted non-commercial use, distribution, and reproduction in any medium, provided the original work is properly cited.
같은 헤드 마운트 디스플레이(head mount display)가 Heilig 에 의해 개발되어 20세기 후반부터 군사 및 산업 분야에서 쓰 였다. 2) 2010년대 들어 컴퓨터와 디스플레이 기술의 급격한 발 전으로 일반 대중들을 위한 VR 산업이 등장하였고, 그 혁신 성과 대중성으로 인해 게임과 엔터테인먼트를 중심으로 급격 히 확산될 것으로 생각되었으나 현 시점에서 여러 문제를 해 결하지 못해 예상보다 낮은 점유율을 보이고 있으며, 2021년 8월 VR 사용자의 숫자는 게임 상거래 사이트인 Steam 월별 사용자 기준으로 전체 게임 이용자 중 $3 \%$ 이하로 집계되고 있다. ${ }^{3)}$ 특히 VR 사용으로 인한 어지러움은 사이버멀미로 명 
명되며, 가장 흔하면서도 교정이 어려워 VR 대중화에 가장 큰 장애물로 꼽히고 있다. ${ }^{4)}$

멀미가 일어나는 이유로 시각 정보와 전정기관, 고유감각 정보가 서로 불일치하는 데에서 멀미가 발생한다는 감각 충 돌이론이 가장 널리 받아들여지고 있으며, 사이버멀미도 마찬 가지로 설명되고 있다." $\mathrm{VR}$ 이 대중들에게 상용화되기 이전에 도 산업 및 군사적으로 이용되어 왔으므로 VR로 인한 멀미 는 이전부터 알려져 있었으며, Kennedy 등이 1993년 미 해군 비행 시뮬레이터 사용자들을 연구하여 멀미를 계량화하는 지수를 개발한 이래로 사이버멀미를 경감시키기 위한 연구가 계속되어 왔다. ${ }^{6}$ 사이버멀미를 경감시키는 방법으로 현재까 지 Point-and-Teleport method, 시점 변화에 대한 가상현실 내 선행지표 제시, 시야각 제한, 약물 처방 등 많은 방법이 시 도되고 있으며, 그 중에서 시야각 제한과 Point-and-Teleport method의 경우 상용화된 많은 VR 소프트웨어에서 멀미를 줄이기 위해 사용되고 있다. ${ }^{7)}$ 그러나 현재까지 상용화된 방법 중 멀미를 획기적으로 감소시키는 방법은 없는 상태이다. ${ }^{7)}$

최근 Weech 등 ${ }^{8)}$ 이 유양돌기에 진동자극을 적용하는 방식 으로 사이버멀미를 조절하는 방법을 제시하였고, 연구 결과 유의미한 증상 감소를 보였다. 본 연구에서는 유양돌기에 진 동자극을 적용하는 방법이 실제로 사이버멀미 저감에 효과가 있는지를 확인하고 보완 및 실용화 가능성 여부에 대해 탐구 하고자 한다.

\section{대상 및 방법}

자발적인 지원자 중 기저질환이 있거나 이전에 심한 어지 러움, 멀미의 기왕력이 없는 건강한 젊은 성인 남성(평균 나

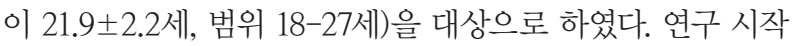
전 병력청취 및 소뇌기능검사, 안진검사, 이과적인 신체검진을 시행하였으며, 실험 당일 건강에 이상이 있거나 난청 및 어지 러움을 유발하는 과거질환이나 그 외 중이염 등 이과적인 질 환의 과거력이 있는 자는 연구 대상에서 제외하였다. 이전에 교통수단, 놀이기구 경험에 대해 연구 시작 전 문진을 시행하 여, 최근 수 년 간 승용차, 버스, 기차, 비행기, 배, 회전목마, 롤러코스터 등을 이용했을 때 구토나 오심, 그 외에 일상생활 에 지장이 있을 정도의 어지러움 및 멀미 증상이 있는지를 확 인하고, 해당 멀미 병력이 확인된 자는 연구 대상에서 제외하 였다. 그 외에 실험 참가자들이 이전에 VR을 사용한 경험 유 무와 빈도, 가장 최근의 VR 경험을 확인하였다.

실험군과 대조군은 단순무작위배정을 통해 배정하였으며, 실험 당일 실험자가 도착한 순서대로 난수표의 해당하는 번 호에 맞도록 그룹을 분류하였다. 모든 연구 대상자는 실험 전 병력청취 및 검진 후 이상이 없음을 확인한 상태에서 $\mathrm{VR}$ headset을 착용하였다. VR headset은 Playstation VR (Sony Interactive Entertainment Inc., Tokyo, Japan) (Fig. 1A)을 사용하였고, 착용 후 초점 일치 및 불쾌감이 있는지 여부를 확인하였다. 사용자가 움직일 가상현실세계 프로그램은 게임 소프트웨어(Elder Scroll 5: Skyrim VR; ZeniMax Media
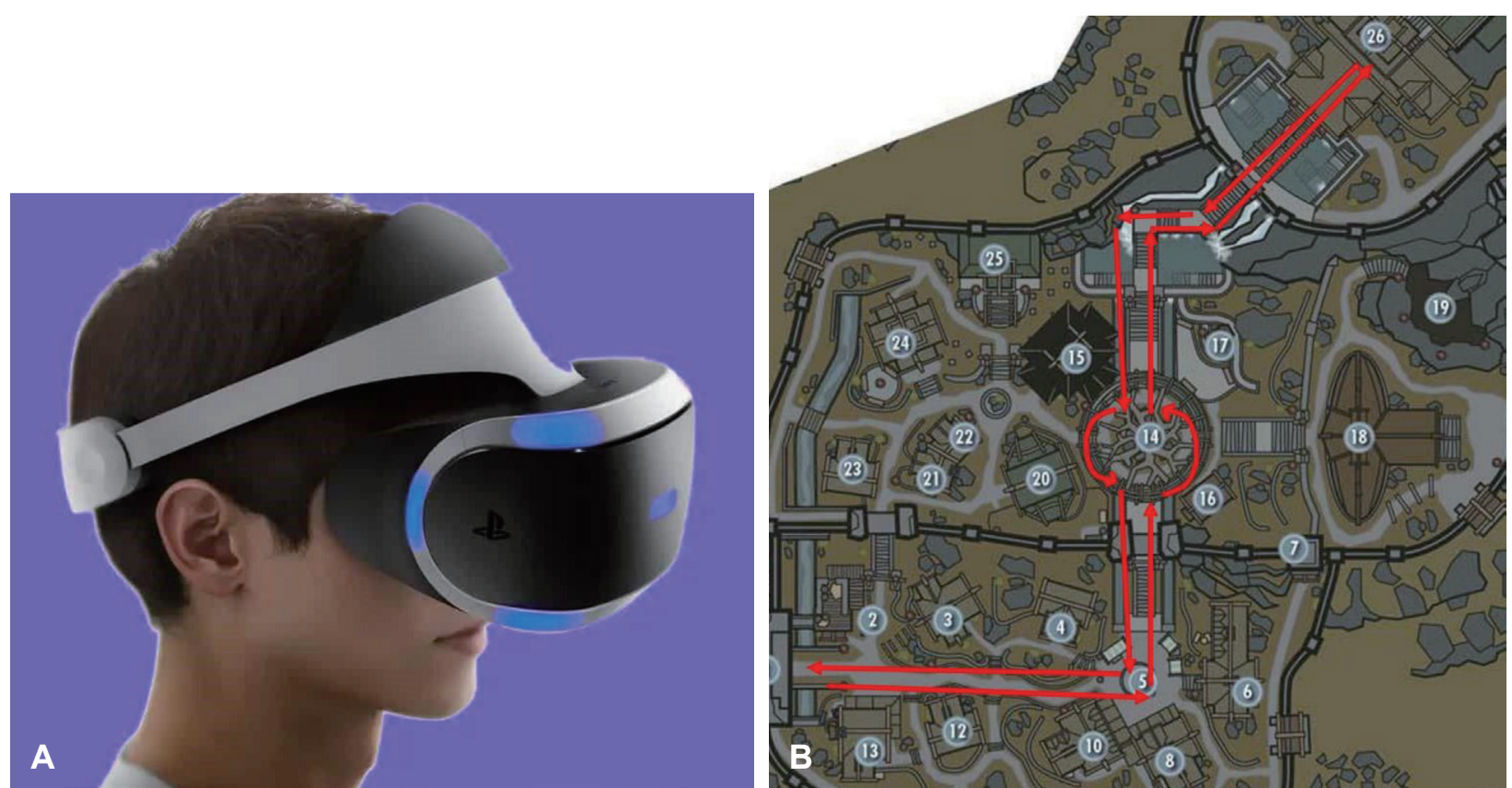

Fig. 1. Virtual environment in experiment. A: Playstation VR (Sony Interactive Entertainment Inc.) is used as headmount display to visualize the virtual environment. B: Top-down view of the participant's path in virtual environment. 
Inc.; Washington, DC; USA)을 사용하였으며, 가상현실 내 의 고정된 경로로만 이동하도록 실험을 설계하였다(Fig. 1B). 실험 전 피험자가 움직일 경로 및 조작방법에 대해 교육하고 숙지하도록 하였다.

실험군에게는 VR headset 외에 추가로 양측 유양돌기 부 위에 진동자극을 일으킬 수 있는 두피마사지 기계 HMS-05 (actto Inc., Seoul, Korea)를 사용하였다. 실험군 참가자들 은 두피마사지 기계의 진동부분이 접착된 고무헤어밴드를 착 용하였으며, 실험 시간 동안 참가자 각자에게 일정한 진동자 극이 전달될 수 있도록 헤어밴드 길이를 실험 참가자 머리에 맞게 조절하여 진동부위가 유양돌기에 밀착하게 하였다. 실 험은 1 인당 약 10 분 내로 마칠 수 있도록 시행되었고 항상 실 험자가 실험 과정을 관찰하였으며, 사이버멀미의 증상이 심 해지면 즉시 실험자에게 증상을 이야기하고 실험을 중단할 수 있도록 교육하였다. 실험자는 참가자가 VR 체험하는 과정 을 관찰하면서 가능한 일정한 속도로 이동하도록 안내하여 각 실험 간 환경 차이가 크지 않도록 조절하였다.

실험 이후에는 참가자의 컨디션을 확인하고 사이버멀미 측 정을 위해 simulator sickness questionnaires (SSQ) 설문지 를 시행하여 사이버멀미를 계량화하였다. ${ }^{9}$ 모든 통계적 처리 는 SPSS 27.0판(IBM Corp., Armonk, NY, USA)을 이용하 여 실시하였다. SSQ는 증상의 정도에 따른 전체 증상값(total severity score)과, 구역질이나 구토 증상(nausea), 눈의 피로 와 같은 안구 운동 불편(oculomotor), 방향감각 상실(disorientation) 등의 3 가지 하위 증상값을 구할 수 있게 구성되어 있는 지표로, 각각의 어지러움 척도들을 두 그룹에 대한 independent t-test로 비교하여 통계적으로 유의미한 차이가 있는지 확인하였다(Tables 1 and 2). 각각의 변수들은 평균 \pm 표준편차의 형식으로 기술되었고, 유의수준은 0.05 미만을 의미있는 것으로 해석하였다. 이 연구는 공용 기관윤리심의 위원회의 심의를 통과하였으며, 실험 참여자에게 실험 내용 을 설명하고 동의서를 취득하여 연구를 진행하였다(P01202009-11-002).

\section{결 과}

총 54명의 젊은 성인을 대상으로 실험하였으며, 참가자 중 교통수단 및 놀이기구에서 최근 수년 내에 일상생활에 지장 을 줄 정도의 멀미를 경험한 사람은 없었다. 이전 VR 경험은 참가자 모두 3 회 미만이었으며, 최근 1 개월간 $\mathrm{VR}$ 을 사용한 사람은 없었고, 실험에 사용된 VR 소프트웨어를 미리 경험한 참가자도 없었다. 실험군과 대조군은 각각 27명씩이었으며, 실험 도중 실험군과 대조군에서 각각 6명이 실험 도중 심한
어지러움을 호소하여 실험을 중단하였고, 안정 및 회복하면 서 설문지를 작성하였다.

실험군에서 total severity score의 평균은 46.7 $\pm 49.0(0-$ 183.3)이었고, nausea score는 평균 $39.2 \pm 44.9$ (0-162.2),

Table 1. Simulator sickness questionnaire

\begin{tabular}{lcccc}
\hline & $\begin{array}{c}\text { 증상 } \\
\text { 없음 }\end{array}$ & $\begin{array}{c}\text { 약한 } \\
\text { 증상 }\end{array}$ & $\begin{array}{c}\text { 보통 } \\
\text { 증상 }\end{array}$ & $\begin{array}{c}\text { 심한 } \\
\text { 증상 }\end{array}$ \\
\hline 1. 전반적인 불편 & 0 & 1 & 2 & 3 \\
2. 피로 & 0 & 1 & 2 & 3 \\
3. 두통 & 0 & 1 & 2 & 3 \\
4. 눈의 피로 & 0 & 1 & 2 & 3 \\
5. 눈의 초점 맞추기 어려움 & 0 & 1 & 2 & 3 \\
6. 침 분비의 증가 & 0 & 1 & 2 & 3 \\
7. 발한 & 0 & 1 & 2 & 3 \\
8. 메스꺼움 & 0 & 1 & 2 & 3 \\
9. 집중하기 곤란함 & 0 & 1 & 2 & 3 \\
10. 머리가 꽉 찬 느낌 & 0 & 1 & 2 & 3 \\
11. 뿌연 시야 & 0 & 1 & 2 & 3 \\
12. 눈을 떴을 때의 현기증 & 0 & 1 & 2 & 3 \\
13. 눈을 감았을 때의 현기증 & 0 & 1 & 2 & 3 \\
14. 빙빙 도는 느낌의 어지러움 & 0 & 1 & 2 & 3 \\
15. 위에 대한 부담감 & 0 & 1 & 2 & 3 \\
16. 트림 & 0 & 1 & 2 & 3 \\
\hline
\end{tabular}

Table 2. Computation of SSQ scores

\begin{tabular}{|c|c|c|c|}
\hline SSQ symptoms & Nausea & Oculomotor & Disorientation \\
\hline 1. 전반적인 불편 & 1 & 1 & \\
\hline 2. 피로 & & 1 & \\
\hline 3. 두통 & & 1 & \\
\hline 4. 눈의 피로 & & 1 & \\
\hline 5. 눈의 초점 맞추기 어려움 & & 1 & 1 \\
\hline 6. 침 분비의 증가 & 1 & & \\
\hline 7. 발한 & 1 & & \\
\hline 8. 메스꺼움 & 1 & & 1 \\
\hline 9. 집중하기 곤란함 & 1 & 1 & \\
\hline 10. 머리가 꽉 찬 느낌 & & & 1 \\
\hline 11. 뿌연 시야 & & 1 & 1 \\
\hline 12. 눈을 떴을 때의 현기증 & & & 1 \\
\hline 13. 눈을 감았을 때의 현기증 & & & 1 \\
\hline $\begin{array}{l}\text { 14. 빙빙 도는 느낌의 } \\
\text { 어지러움 }\end{array}$ & & & 1 \\
\hline 15. 위에 대한 부담감 & 1 & & \\
\hline 16. 트림 & 1 & & \\
\hline Total & [1] & [2] & [3] \\
\hline Nausea $=[1] \times 9.54$ & & & \\
\hline Oculomotor $=[2] \times 7.58$ & & & \\
\hline Disorientation $=[3] \times 13.92$ & & & \\
\hline $\mathrm{TS}=([1]+[2]+[3]) \times 3.74$ & & & \\
\hline
\end{tabular}

SSQ, simulator sickness questionnaire; Total, sum obtained by adding symptom scores; TS, total severity score 
oculomotor score는 평균 30.9 \pm 32.1 (0-128.9), disorientation score는 평균 59.8 \pm 62.8 (0-208.8)이었다. 대조군에서 total severity score의 평균은 44.9 \pm 45.1 (0-194.9)이었고, nausea score는 평균 34.3 \pm 38.9 (0-143.1), oculomotor score는 평

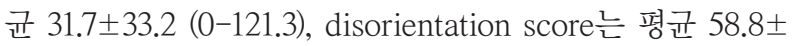
57.0 (0-236.6)이었다. 점수분포가 모두 정규분포를 따른 것 으로 확인되어 independent t-test를 시행하였으며, 사이버멀 미의 total severity score와 3가지 하위 증상값 모두 실험군 과 대조군 사이에 유의미한 차이를 보이지 않았다(Fig. 2).

실험에서 탈락한 12 명을 통계에서 제외하고 분석한 경우 에는 실험군에서 total severity score의 평균은 $30.8 \pm 37.8$

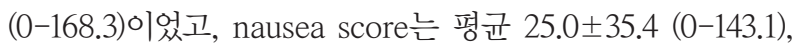
oculomotor score는 평균 21.7 25.4 (0-113.7), disorientation score는 평균 38.4 \pm 46.6 (0-208.8)이었다. 대조군에서 total severity score의 평균은 31.5 \pm 35.3 (0-153.3)이었고, nausea score는 평균 20.9 \pm 27.4 (0-104.9), oculomotor score 는 평균 23.8 \pm 27.8 (0-121.3), disorientation score는 평균 $43.1 \pm 45.9$ (0-194.9)였다. 점수분포가 모두 정규분포를 따른

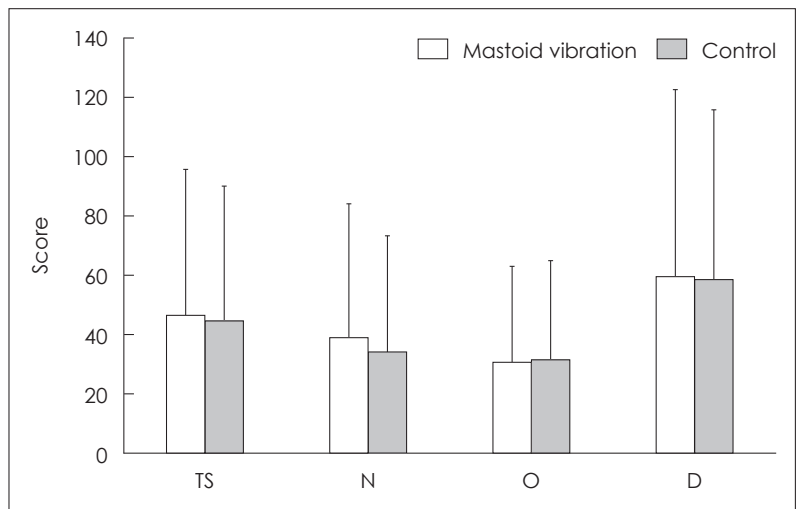

Fig. 2. Simulator sickness questionnaire scores of experimental group and control group. TS, total severity score; N, nausea score; $\mathrm{O}$, oculomotor score; $\mathrm{D}$, disorientation score.

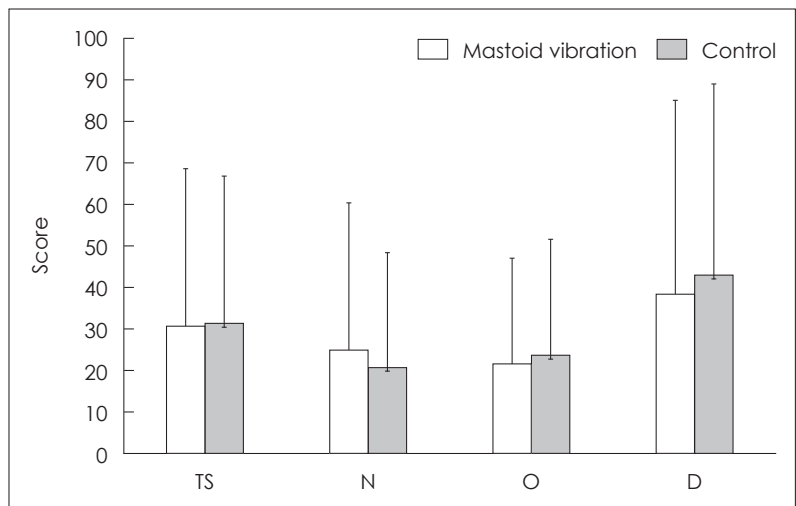

Fig. 3. Simulator sickness questionnaire scores of experimental group and control group without failed participants. TS, total severity score; $\mathrm{N}$, nausea score; $\mathrm{O}$, oculomotor score; $\mathrm{D}$, disorientation score.
것으로 확인되어 independent t-test를 시행하였으며, 마찬가 지로 total severity score와 3가지 하위 증상값 모두 실험군 과 대조군 사이에 유의미한 차이를 보이지 않았다(Fig. 3).

실험 참가자들이 VR을 체험한 시간은 실험군에서 $376.2 \pm$ 125.2초(376-640초)였고, 대조군에서 370.9 109.5 초(375650 초)였다. 점수분포가 정규분포를 따른 것으로 확인되어 시행한 independent t-test에서 실험군과 대조군은 유의미한 차이를 보이지 않았다 $(p=0.43)$.

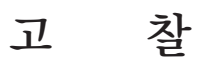

사이버멀미는 $\mathrm{VR}$ 의 상용화에서 흔히 관찰되는 문제점으 로, VR 게임에 대한 메타분석에서 어지러움으로 인한 탈락 율이 44\%-100\%로 보고될 정도로 교정이 어렵다. ${ }^{10)}$ 현재 사 이버멀미를 해결하기 위해 가장 흔하게 시도되는 방법은 움 직임에 대한 안정된 지표를 제시하거나, 움직임에 제약을 두 어 시각 가속 및 회전 움직임을 최소화하기, 시야각 줄이기 등 VR 소프트웨어에 현실과 구분되는 제약을 두는 방법으 로, 이 중 여러가지가 현재 상용화된 VR 프로그램에 적용되 어 있으나 다수의 이용자에서 효과적으로 멀미를 제거하지는 못하고 있다.711) 다른 방법은 VR 사용자의 몸에 직접적으로 간섭하여 체감되는 멀미를 줄이는 방법으로, 반복되는 VR 경험을 이용한 적응 최적화, 멀미약 처방, 유양돌기를 통해 전 정계에 전기자극을 주는 방법(galvanic vestibular stimulation) 등이 제시되어 있다. ${ }^{7,1213)}$ 감각충돌이론에 기반을 두고 있는 이러한 접근법들은 실험실 내의 연구에서는 어느 정도 그 효과가 입증되었으나, VR 사용자에게 부작용을 일으킬 우 려가 많아 상용화된 제품에서 널리 쓰이고 있지는 않다. ${ }^{14,15)}$

최근 사이버멀미를 조절하기 위한 방안으로 유양돌기의 진 동자극이 유효하다는 주장이 제시되었으며, 관련 특허도 승 인된 상태이다. ${ }^{8)}$ 유양돌기의 진동자극이 멀미 및 사이버멀미 를 감소시키는 것에 대한 이론적인 근거는 Bayesian cue integration이다. ${ }^{16,17)}$ 뇌에서 외부 상황을 감지할 때는 여러 가지 감각을 통합하여 판단하게 되는데, 서로 다른 자극이 각자 상 충되는 신호를 보내게 될 경우 뇌는 그 중 더 신뢰할 수 있을 만한 감각에 가중치를 두어 판단하고 신뢰할 수 없는 감각은 상황에 맞게 가공하거나 무시하게 된다. Theodor와 Kohler 가 시행한 유명한 실험이 이러한 적응의 대표적인 예로, 상하 시야를 거꾸로 반전시키는 안경을 착용했을 때 피험자는 처 음에는 혼란을 겪었으나, 약 1 주일 뒤부터는 뇌에서 시각 정 보가 다른 감각과 거꾸로 되어 있음에 적응하고 시각 이미지 를 뇌가 다시 반전시켜서 인식했기 때문에 안경 착용자는 상 하가 바뀌지 않은 시야를 보게 되었다. ${ }^{18)}$ 이번 사이버멀미 실 
험에서도 같은 원리를 이용하였는데, 안구에서 보내주는 시 각신호와 내이에서 보내주는 평형감각 신호가 서로 불일치할 경우 멀미가 일어나지만, 유양돌기에 대해 진동자극을 주어 외부상황과 맞지 않는 noise가 지속적으로 전달되면, 뇌에서 는 내이로부터 오는 진동신호를 덜 신뢰할 만한 신호로 인식 하여 시각정보에 더 가중치를 둠으로써 멀미를 미리 방지할 수 있을 것이라고 예측한 것이다.

본 연구에서는 유양돌기 진동자극이 사이버멀미를 감소시 킬 것을 예상하고 실험하였으나 기존 연구와는 다르게 유양돌 기 진동자극이 사이버멀미를 유의미하게 줄여주지 못하였다. 실험군과 대조군에서 사이버멀미의 total severity score 및 하위지표 3가지 모두 유의미한 차이를 나타내지 못했으며, 실 험을 완수한 숫자와 중간에 탈락한 숫자도 모두 동일하였다.

실험 결과에 차이가 나타난 이유로, 이전에 실시한 연구에 서는 현실세계와 다르게 구와 평면으로 이루어진 단순화된 가상세계에서 실험을 실시한 반면, 본 실험은 현실세계와 유 사한 게임 소프트웨어로 실험을 실시하였고 그에 따라 멀미 의 강도가 크게 증가했다고 생각할 수 있다. 실제로 유양돌기 에 진동자극을 주지 않은 대조군끼리 비교했을 때 Weech 등 ${ }^{8}$ 의 실험에서는 total severity score가 약 25점으로 나온 반면, 본 실험에서는 약 45점이 나와 본 실험의 피험자들이 횔씬 강한 멀미를 보였다. 또한 Weech 등의의 연구에서는 실험 도중 탈락한 피험자가 없었으나 본 연구에서는 실험군과 대조군 각 27명 중 각각 6명씩이 어지러움으로 실험을 끝까지 수행 하지 못했으며, 실험을 완수한 경우에만 한정했을 때에도 대 조군의 total severity score는 약 31점으로 기존 연구보다 심 한 멀미를 보였다. 따라서 유양돌기 진동자극은 약한 멀미를 일으키는 환경에서는 멀미를 감소시킬 수 있을 정도의 효과 를 내지만, 강한 멀미를 일으키는 자극 조건에서 멀미를 경감 시키기에는 아직 효과가 부족하다고 추론할 수 있다.

그 외에 이번 연구에서는 어지러움 자극 조건과 유양돌기 진동 자극을 커플링시켜서 시행하지 않았다. Weech 등8의 연 구에서는 가속이나 회전 등 멀미가 일어날 만한 자극이 있을 때 유양돌기 진동자극도 함께 주어지도록 커플링 하였고, 그 외에도 진동자극을 무작위로 주는 그룹도 함께 실험하여 진 동자극의 효과를 시험하였는데, 그 결과 진동자극이 커플링 된 그룹이 가장 멀미가 적었고 진동자극이 랜덤하게 주어진 그룹이 그 다음으로 적었으며, 진동자극이 주어지지 않은 대 조군이 가장 멀미가 많았다. 그러나 본 연구에서는 예산과 장 비의 제약으로 진동자극을 어지러움 자극과 커플링시킬 수 없어, 진동자극을 실험 시간 동안 계속 지속되도록 하였다. 앞서 제시한 Bayesian cue integration의 원리에 따르면 지속 적인 진동자극도 사이버멀미를 감소시킬 수 있다고 추론할
수 있으며, Weech 등 ${ }^{8}$ 의 논문에서도 이에 대한 후속 연구가 필요하다고 언급한 바 있다. 그러나 어지러움 감소효과 정도 는 진동자극을 주는 방식에 따라 달라질 수 있으므로, 추후 여러 가지 조건에서 유양돌기 진동 자극을 주도록 세팅하는 후속 연구를 통해 비교할 수 있을 것이다.

진동수의 차이 또한 어지러움 조절에 영향을 미쳤을 수 있 다. 본 연구에서 사용한 두피 안마기는 약 $133 \mathrm{~Hz}$ 의 진동수 를 가지고 있으며, Weech 등의 의 연구에서는 유양돌기에 500 $\mathrm{Hz}$ 의 진동자극이 주어졌다. 골전도 진동자극이 구형낭에 미 치는 영향을 VEMP로 측정했을 때, 반복되는 자극하에서 내 이의 반응이 가장 높은 진동수는 200-400 Hz라는 보고가 있으므로 ${ }^{19)}$ 이 범위에 해당하는 진동수로 실험할 경우 멀미 감소 효과를 더 높일 수 있을 것이라고 생각할 수 있다.

Weech 등 ${ }^{8}$ 의 선행 연구에서는 실험 중 이동속도가 인위적 으로 항상 일정하게 유지되었던 반면, 본 연구에서는 움직임 을 모두 참가자 본인이 직접 조종하였다. 연구자는 실험이 진 행되는 동안 그 과정을 참관하며 지나치게 빠르거나 느리게 이동하지 않고 약 10 분 내로 실험이 끝날 수 있도록 조절하였 다. 양쪽 군에서 실험을 시행한 시간에 통계적인 차이가 없었 으므로 실험군과 대조군이 비슷한 속도로 움직였다고 볼 수 있으나, 실험 중 이동속도를 고정시킨 선행연구와는 다소 차 이가 있다. 따라서 본 연구는 기존 연구에 비해 VR 움직임의 복잡성이 더 커졌으며, 이 또한 연구 결과의 차이에 영향을 미 쳤을 수 있다.

상기 내용을 종합했을 때, 본 연구에서는 기존 연구와 다 르게 유양돌기에 대한 진동자극이 사이버멀미를 감소시키지 못하였다. 그러나 본 연구는 선행된 Weech 등의 의 연구와 여러 조건이 다르게 시행되었다. VR 환경은 기존 연구보다 횔씬 현실에 가까운 소프트웨어를 사용하여 멀미를 일으킬 수 있 는 강도가 높아졌고, 진동자극 또한 기존 연구와 다른 진동 수와 조건에서 주어졌으며, 실험 참가자가 직접 움직임을 조 종하여 움직임의 복잡성 또한 커졌다. 따라서 본 연구 결과를 통해 Weech 등이이 주장한 진동자극이 사이버멀미를 경감시 키는 효과를 부정할 수는 없으며, 선행 연구를 검증하기 위 해서는 기존 연구 조건에 더 가깝게 제작한 장비를 이용한 후속 연구가 필요하다. 다만 본 연구의 VR 체험은 현재 상용 화된 소프트웨어에서, 현실과 더 가까운 이동방식을 통해 이 루어진 만큼 현실 VR 사용자들이 체험하는 가상현실에 더 가까운 조건에서 실험이 행해졌다는 이점이 있다. 또한 국내 에서는 이 주제에 대해 공개된 연구가 아직 행해진 바 없어 후속 연구자들이 연구를 계획할 때에 Weech 등의 의 연구와 함께 연구 세팅에 참고할 수 있을 것이다.

유양돌기 진동자극이 어지러움을 줄이는 긍정적인 효과 외 
에 오히려 어지러움을 유발하지 않는지에 대한 고찰 또한 필 요하다. 단시간의 두부 진동자극은 내이질환이 없는 일반인 구에서는 의미 있는 어지러움이나 안진을 일으키지 않는다는 보고가 있으며, ${ }^{20)}$ 현재 상용화된 두피진동마사지기가 사용자 에게 어지러움을 일으킨다는 보고도 없으므로 본 연구에서 진동자극이 오히려 어지러움을 일으켰을 가능성은 크지 않 을 것으로 생각된다. 그러나 진동자극의 세기가 지나치게 크 면 사용자의 시야까지 흔들려 어지러움을 유발할 이론적인 가능성도 존재하므로 진동자극의 세기가 너무 커지지 않도 록 주의할 필요성이 있다. 또한 다수의 인구가 장기간 유양돌 기 진동자극을 사용할 경우 발생할 수 있는 부작용도 고려해 야 한다. 장시간 지속되는 진동에 의해 난청 및 benign paroxysmal positional vertigo가 발생할 수 있다는 보고가 있으 며, ${ }^{21,22)}$ 다수의 대중에게 내이 진동자극이 시행된 바가 없으 므로 그 외 다른 종류의 부작용 발생 가능성도 염두에 두어 야 할 것이다.

결론적으로, 이번 실험에서는 유양돌기 진동자극을 이용한 사이버멀미 감소 효과를 입증하지 못했다. 진동수를 조절하 거나 진동자극과 어지러움 조건을 커플링시키는 등의 추가적 인 조치로 효과 개선을 기대해 볼 수 있다. 그러나 현실적이고 복잡한 VR 조건에서는 어지러움 또한 심해질 것이며, $\mathrm{VR}$ 의 대중화를 위해서는 아직도 많은 추가 연구를 통해 어지러움 을 획기적으로 개선시킬 방안이 필요할 것이다.

\section{Acknowledgments}

This study was executed with author's own expense and without fundraising.

\section{Author Contribution}

Conceptualization: Eunsub Lee. Data curation: Juyong Kang. Formal analysis: Juyong Kang. Investigation: Eunsub Lee. Methodology: Eunsub Lee. Project administration: Eunsub Lee. Resources: Eunsub Lee. Software: Eunsub Lee. Supervision: Eunsub Lee. Validation: Eunsub Lee. Visualization: Minsuk Chae. Writing — original draft: Minsuk Chae. Writing_review \& editing: Eunsub Lee.

\section{ORCID}

Eunsub Lee

$$
\text { https://orcid.org/0000-0002-7211-2074 }
$$

\section{REFERENCES}

1) Jerald J. What is virtual reality? In: Jerald J, editor. The VR Book: Human-Centered Design for Virtual Reality. 1st ed. Seoul: Acorn Publishing;2019. p.39-43.

2) Jerald J. History of virtual reality. In: Jerald J, editor. The VR Book: Human-Centered Design for Virtual Reality. 1st ed. Seoul: Acorn Publishing;2019. p.45-58.

3) Lang B. VR on steam bounces back to nearly 2.8 million monthlyconnected headsets [Internet]. Austin, TX: Road to VR; 2021 [cited 2021 Aug 2]. Available from: URL: https://www.roadtovr.com/ steam-survey-vr-headsets-on-steam-data-july-2021/.

4) Jerald J. Adverse health effect. In: Jerald J, editor. The VR Book:
Human-Centered Design for Virtual Reality. 1st ed. Seoul: Acorn Publishing;2019. p.199-202.

5) Harm DL. Motion sickness neurophysiology, physiological correlates, and treatment. In: Hale KS, Stanney KM, editors. Handbook of Virtual Environments: Design, Implementation, and Applications. 1st ed. Boca Raton: CRC Press;2002. p.677-702.

6) Jerald J. Measuring sickness. In: Jerald J, editor. The VR Book: Human-Centered Design for Virtual Reality. 1st ed. Seoul: Acorn Publishing;2019. p.239-41.

7) Jerald J. Examples of reducing adverse effects. In: Jerald J, editor. The VR Book: Human-Centered Design for Virtual Reality. 1st ed. Seoul: Acorn Publishing;2019. p.253-61.

8) Weech S, Moon J, Troje NF. Influence of bone-conducted vibration on simulator sickness in virtual reality. PLoS One 2018;13(3): e0194137.

9) Kennedy RS, Lane NE, Berbaum KS, Lilienthal MG. Simulator sickness questionnaire: An enhanced method for quantifying simulator sickness. Int J Aviat Psychol 1993;3(3):203-20.

10) Saredakis D, Szpak A, Birckhead B, Keage HAD, Rizzo A, Loetscher T. Factors associated with virtual reality sickness in head-mounted displays: A systematic review and meta-analysis. Front Hum Neurosci 2020;14:96.

11) Fernandes AS, Feiner SK. Combating VR sickness through subtle dynamic field-of-view modification. Proceedings of the 2016 IEEE Symposium on 3D User Interfaces (3DUI); 2016 March 19-20; Greenville, SC: IEEE;2016. p.201-10.

12) Reed-Jones RJ, Reed-Jones BH, Trick LM, Vallis LA. Can galvanic vestibular stimulation reduce simulator adaptation syndrome? Proceedings of the Driving Assessment Conference 2007; 2007 July 9-12; Iowa City, IA: University of Iowa;2007. p.534-40.

13) Byun H, Park CW. Introduction of cybersickness. Korean J Otorhinolaryngol-Head Neck Surg 2019;62(10):545-53.

14) Keshavars B, Hecht H, Lawson BD. Visually induced motion sickness: Characteristics, causes, and countermeasures. In: Hale KS, Stanney KM, editors. Handbook of Virtual Environments: Design, Implementation, and Applications. 2nd ed. Boca Raton: CRC Press;2014. p.648-97.

15) Utz KS, Korluss K, Schmidt L, Rosenthal A, Oppenländer K, Keller $\mathrm{I}$, et al. Minor adverse effects of galvanic vestibular stimulation in persons with stroke and healthy individuals. Brain Inj 2011; 25(11):1058-69.

16) Ernst MO, Banks MS. Humans integrate visual and haptic information in a statistically optimal fashion. Nature 2002; 415(6870):429-33.

17) Greenlee MW, Frank SM, Kaliuzhna M, Blanke O, Bremmer F, Churan J, et al. Multisensory integration in self motion perception. Multisensory Res 2016;29(6-7):525-56.

18) Sachse P, Beermann U, Martini M, Maran T, Domeier M, Furtner MR. "The world is upside down" - The Innsbruck Goggle Experiments of Theodor Erismann (1883-1961) and Ivo Kohler (1915-1985). Cortex 2017;92:222-32.

19) Sheykholeslami K, Habiby Kermany M, Kaga K. Frequency sensitivity range of the saccule to bone-conducted stimuli measured by vestibular evoked myogenic potentials. Hear Res 2001;160(1-2): 58-62.

20) Perez N. Vibration induced nystagmus in normal subjects and in patients with dizziness. A videonystagmography study. Rev Laryngol Otol Rhinol (Bord) 2003;124(2):85-90.

21) Sutinen P, Zou J, Hunter LL, Toppila E, Pyykkö I. Vibrationinduced hearing loss: Mechanical and physiological aspects. Otol Neurotol 2007;28(2):171-7.

22) Amir I, Young E, Belloso A. Self-limiting benign paroxysmal positional vertigo following use of whole-body vibration training plate. J Laryngol Otol 2010;124(7):796-8. 